\title{
Ultra-short-course booster allergen immunotherapy
}

\author{
O Pfaar*, 1,2, U Pieper-Fürst ${ }^{3} \&$ R Mösges ${ }^{3}$ \\ ${ }^{1}$ Department of Otorhinolaryngology, Head \& Neck Surgery, Medical Faculty Mannheim, Universitätsmedizin Mannheim, \\ Heidelberg University, Mannheim, Germany \\ ${ }^{2}$ Center for Rhinology \& Allergology, Wiesbaden, Germany \\ ${ }^{3} \mathrm{CRI}$-Clinical Research International Ltd, Cologne, Germany \\ *Author for correspondence: oliver@pfaar.org
}

' these results demonstrated the efficacy of the ultra-short-course subcutaneous AIT with MPL ${ }^{\circledR}$ as a booster therapy for patients with recurrent grass pollen-induced allergic rhinoconjunctivitis after a previous SCIT or SLIT"'

First draft submitted: 14 February 2018; Accepted for publication: 2 March 2018; Published online: 22 March 2018

Keywords: booster $\bullet$ combined symptom and medication score $\bullet$ grass pollen allergy $\bullet$ revaccination $\bullet$ subcutaneous allergen immunotherapy

Allergen immunotherapy (AIT) represents the only treatment option with a disease-modifying effect on the IgE-mediated inflammatory immune response in allergic patients [1-5]. Both routes of administration, sublingual (SLIT) and subcutaneous immunotherapy (SCIT), had demonstrated clinical efficacy and safety [6-8]. However, despite initially reported alleviation of allergic complaints, a relevant proportion of patients suffered from recurrent symptoms some years after the cessation of the AIT [9-11].

Several innovative approaches in AIT, including adjuvant vaccines, have been developed and already moved into the clinical phase [12]. The ultra-short course subcutaneous AIT (POLLINEX ${ }^{\circledR}$ Quattro Plus 1.0 ml; Bencard ${ }^{\circledR}$ Allergy GmbH, Munich, Germany) using tyrosine-adsorbed grass pollen allergoids and monophosphoryl lipid A $\left(\mathrm{MPL}^{\circledR}\right)$ as an adjuvant has proven its clinical efficacy and safety in pollen-allergic patients [13-16]. The treatment consists of four pre-seasonal injections of $300 \mathrm{SU}, 800 \mathrm{SU}$ and $2000 \mathrm{SU}$ (twice), according to the summary of product characteristics [17].

Recently, we investigated this ultra-short-course subcutaneous AIT as a booster therapy in patients with grass pollen-induced allergic rhinoconjunctivitis who had completed any kind of grass pollen AIT (SLIT or SCIT) at least 5 years prior to study start with initial reduction of symptoms in the first years after the treatment, but then suffered from recurrent symptoms of grass pollen allergy [18]. The study was designed as a prospective, controlled, nonrandomized, patient-preference, non-interventional study (NIS) carried out in 14 study centers in Germany from March to September 2015. After consulting with their allergists, patients (12 years of age or older) chose whether they received one course of ultra-short AIT before the grass pollen season or not. During the season, all patients received (standardized) symptomatic medication according to the EAACI Position Paper [19] free of charge via an Internet pharmacy. $56(52.3 \%)$ patients chose the booster AIT in combination with symptomatic medication if needed during the grass pollen season (booster AIT group) and 51 (47.7\%) preferred to take symptomatic medication exclusively (control group). The study consisted of seven visits for booster AIT patients: four treatment visits (V1 to V4) before and three visits during the grass pollen season (V5 at the beginning of the season, V6 during the peak season, and V7 at the end of the season). Patients of the control group had four visits: one (V1) at the study start and three (V5 to V7) during the grass pollen period.

The definition of the peak pollen period was based on data from the German Weather Service, Medicine Meteorology (Deutscher Wetterdienst Meteorologie; www.dwd.de). The regional peak pollen period was defined as those consecutive 30 days with the highest pollen concentration, starting from the first detection of moderateto-high pollen counts (stage 2-3) in the nearest pollen count station. 
Patients were asked to keep a diary that provided data for the daily symptom score (dSS), the daily medication score (dMS) and the combined symptom and medication score (CSMS) [19]. During the 30-day peak pollen period, the daily mean CSMS was consistantly lower in the booster AIT group than in the control group. The average daily mean CSMS in the booster AIT group and in the control group was $1.17 \pm 0.93$ and $1.9 \pm 1.14$, respectively. The difference of $38.4 \%$ was statistically significant in favor of the booster AIT group $(\mathrm{p}<0.01)$. Likewise, the dSS and the dMS were $29.3 \%$ and $46.9 \%$ lower in the booster AIT group, respectively. Comparing the booster AIT and the control group, the differences were statistically significant $(\mathrm{p}<0.05$ and $\mathrm{p}<0.01)$.

Retrospective assessments of the intensity of allergic complaints during the grass pollen season 2014 and 2015 were enquired from the patients at the first and last visit, respectively [20]. From 2014 to 2015, the intensity decreased by $57 \%$ in the booster AIT group and by $30 \%$ in the control group. These reductions were statistically significant (each p < 0.001). Remarkably, the reduction of the intensity of allergic symptoms in the booster AIT group was almost twice as much as that in the control group and was statistically significant $(\mathrm{p}<0.05)$ when compared with control.

Analysis of medication intake revealed that the proportion of patients in the booster AIT group who did not use any symptomatic medication during the grass pollen period increased by $30 \%$ from 2014 to 2015 . In the control group, these proportions were almost identical in both years. The difference between the booster AIT group $(34.0 \%)$ and the control group $(2.0 \%)$ in 2015 was statistically significant $(\mathrm{p}<0.001)$.

The above mentioned results were supported by the patients' assessment of their state of health in 2015 in comparison with that in the previous year using the following scale: 'significantly better', 'slightly better', 'unchanged', and 'worse' [21]. The great majority (92\%) of booster AIT patients evaluated their state of health in 2015 as significantly or slightly better. In contrast, in the control group, only $46 \%$ of patients made a similar assessment.

In order to gain information about the impact of the grass pollen allergy on patients' daily life, we asked study participants to complete the Mini Rhinoconjuctivitis Quality of Life Questionnaire (MiniRQLQ) [22] at V1 at the study start (before the grass pollen season) as well as at V5, V6 and V7 during the grass pollen season. The analysis of the MiniRQLQ demonstrated consistently and significantly better quality of life in the booster AIT group than that in the control group at V5, V6, and V7 (Mean outcome: 0.99, 0.87 and 0.48 versus 1.88, 1.43 and 0.94, respectively), whereas the outcome of this questionnaire was similar between the two groups at $\mathrm{V}$.

In conclusion, these results demonstrated the efficacy of the ultra-short-course subcutaneous AIT with MPL ${ }^{\circledR}$ as a booster therapy for patients with recurrent grass pollen-induced allergic rhinoconjunctivitis after a previous SCIT or SLIT that was completed at least 5 years prior to this investigation. Although patients of both treatment groups had access to highly effective symptomatic medication during the pollen season, the booster AIT group showed a greater benefit than the control group, clearly demonstrating the superiority of the booster therapy over the pharmacological treatment alone. The significance of the trial was supported by the analysis of end point variables like CSMS and the MiniRQLQ, as recommended by the EAACI for field trials in AIT [19].

Furthermore, a large proportion of AIT patients evaluated the tolerability of the four injections as 'very good' or 'good' ( 77 to $84 \%$ for each injection). Local reactions at the injection site such as itching and swelling were reported by only $28.6 \%$ of patients. In all, two patients suffered from a mild, grade 1 systemic adverse reaction each. A great majority (96.4\%) of AIT patients did not report any adverse event besides minor discomforts at the injection site. These results, together with the absence of serious adverse events, cases of fatality, anaphylaxis, and the use of epinephrine demonstrated the good safety profile of MPL ${ }^{\circledR}$ enhanced booster therapy.

\section{Acknowledgements}

We would like to thank Dr. Van-Anh Dao for her proofreading and editorial assistance.

Financial \& competing interests disclosure

Dr. Pfaar reports grants and personal fees from ALK-Abelló, grants and personal fees from Allergopharma, grants and personal fees from Stallergenes Greer, grants and personal fees from HAL Allergy Holding B.V./HAL Allergie GmbH, grants and personal fees from Bencard Allergie GmbH/Allergy Therapeutics, grants and personal fees from Lofarma, grants from Biomay, grants from Nuvo, grants from Circassia, grants and personal fees from Biotech Tools S.A., grants and personal fees from Laboratorios LETI/LETI Pharma, personal fees from Novartis Pharma, personal fees from MEDA Pharma, grants and personal fees from Anergis S.A., personal fees from Mobile Chamber Experts (a GA²LEN Partner), personal fees from Pohl-Boskamp, personal fees from Indoor Biotechnologies, grants from Glaxo Smith Kline, outside the submitted work. Dr. Ralph Mösges reports personal fees from ALK, 
grants from ASIT biotech, personal fees from allergopharma, personal fees from Allergy Therapeutics, grants and personal fees from Bencard, grants from Leti, grants, personal fees and non-financial support from Lofarma, non-financial support from Roxall, grants and personal fees from Stallergenes, grants from Optima, personal fees from Friulchem, personal fees from Hexal, personal fees from Servier, personal fees from Klosterfrau, non-financial support from Atmos, personal fees from Bayer, non-financial support from Bionorica, personal fees from FAES, personal fees from GSK, personal fees from MSD, personal fees from Johnson\&Johnson, personal fees from Meda, personal fees and non-financial support from Novartis, non-financial support from Otonomy, personal fees from Stada, personal fees from UCB, non-financial support from Ferrero, grants from BitopAG, grants from Hulka, personal fees from Nuvo, grants from Ursapharm, outside the submitted work. The authors have no other relevant affiliations or financial involvement with any organization or entity with a financial interest in or financial conflict with the subject matter or materials discussed in the manuscript apart from those disclosed.

No writing assistance was utilized in the production of this manuscript.

\section{References}

1. Jutel M, Agache I, Bonini S et al. International consensus on allergy immunotherapy. J. Allergy Clin. Immunol. 136(3), 556-568 (2015).

2. Noon L. Prophylactic inoculation against hay fever. The Lancet 177(4580), 1572-1573 (1911).

3. Durham SR, Leung DY. One hundred years of allergen immunotherapy: time to ring the changes. J. Allergy Clin. Immunol. 127(1), 3-7 (2011).

4. Dhami S, Nurmatov U, Arasi S et al. Allergen immunotherapy for allergic rhinoconjunctivitis: A systematic review and meta-analysis. Allergy 72(11), 1597-1631 (2017).

5. Roberts G, Pfaar O, Akdis CA et al. EAACI Guidelines on Allergen Immunotherapy: Allergic rhinoconjunctivitis. Allergy doi:10.1111/all.13317 (2017).

6. Pfaar O, Bachert C, Bufe A et al. Guideline on allergen-specific immunotherapy in IgE-mediated allergic diseases: S2k Guideline of the German Society for Allergology and Clinical Immunology (DGAKI), the Society for Pediatric Allergy and Environmental Medicine (GPA), the Medical Association of German Allergologists (AeDA), the Austrian Society for Allergy and Immunology (OGAI), the Swiss Society for Allergy and Immunology (SGAI), the German Society of Dermatology (DDG), the German Society of Oto-

Rhino-Laryngology, Head and Neck Surgery (DGHNO-KHC), the German Society of Pediatrics and Adolescent Medicine (DGKJ), the Society for Pediatric Pneumology (GPP), the German Respiratory Society (DGP), the German Association of ENT Surgeons (BV-HNO), the Professional Federation of Paediatricians and Youth Doctors (BVKJ), the Federal Association of Pulmonologists (BDP) and the German Dermatologists Association (BVDD). Allergo. J. Int. 23(8), 282-319 (2014).

7. Calderon MA, Alves B, Jacobson M, Hurwitz B, Sheikh A, Durham S. Allergen injection immunotherapy for seasonal allergic rhinitis. Cochrane Database Syst. Rev doi:10.1002/14651858.CD001936.pub2. 1, CD001936 (2007).

8. Compalati E, Penagos M, Tarantini F, Passalacqua G, Canonica GW. Specific immunotherapy for respiratory allergy: state of the art according to current meta-analyses. Ann. Allergy Asthma Immunol. 102(1), 22-28 (2009).

9. Ebner C, Kraft D, Ebner H. Booster immunotherapy (BIT). Allergy 49(1), 38-42 (1994).

10. Pipet A, Botturi K, Pinot D, Vervloet D, Magnan A. Allergen-specific immunotherapy in allergic rhinitis and asthma. Mechanisms and proof of efficacy. Resp. Med. 103(6), 800-812 (2009).

11. Marogna M, Spadolini I, Massolo A, Canonica GW, Passalacqua G. Long-lasting effects of sublingual immunotherapy according to its duration: a 15-year prospective study. J. Allergy Clin. Immunol. 126(5), 969-975 (2010).

12. Pfaar O, Bonini S, Cardona V et al. Perspectives in allergen immunotherapy: 2017 and beyond. Allergy 73(Suppl. 104), 5-23 (2018).

13. Drachenberg KJ, Proll S, Urban E, Woroniecki SR. Single-course specific immunotherapy with mixed pollen allergoids: results of a multi-centre study. Allergologia et Immunopathologia 31(2), 77-82 (2003).

14. DuBuske LM, Frew AJ, Horak F et al. Ultrashort-specific immunotherapy successfully treats seasonal allergic rhinoconjunctivitis to grass pollen. Allergy Asthma Proc. 32(3), 239-247 (2011).

15. Drachenberg KJ, Wheeler AW, Stuebner P, Horak F. A well-tolerated grass pollen-specific allergy vaccine containing a novel adjuvant, monophosphoryl lipid A, reduces allergic symptoms after only four preseasonal injections. Allergy 56(6), 498-505 (2001).

16. Patel P, Salapatek AM. Pollinex Quattro: a novel and well-tolerated, ultra short-course allergy vaccine. Exp. Rev. Vaccines 5(5), 617-629 (2006).

17. Summary of Product Characteristics. POLLINEX ${ }^{\circledR}$ Quattro Plus $1.0 \mathrm{ml}$.

18. Pfaar O, Lang S, Pieper-Fürst $\mathrm{U}$ et al. Ultra-short-course booster is effective in recurrent grass pollen-induced allergic rhinoconjunctivitis. Allergy 73(1), 187-195 (2018).

19. Pfaar $\mathrm{O}$, Demoly $P$, Gerth Van Wijk R et al. Recommendations for the standardization of clinical outcomes used in allergen immunotherapy trials for allergic rhinoconjunctivitis: an EAACI Position Paper. Allergy 69(7), 854-867 (2014). 
20. Sieber J, Shah-Hosseini K, Mösges R. Specific immunotherapy for allergic rhinitis to grass and tree pollens in daily medical practice-symptom load with sublingual immunotherapy compared to subcutaneous immunotherapy. Annal. Med. 43(6), 418-424 (2011).

21. Shah-Hosseini K, Krudewig EM, Hadler M, Karagiannis E, Mösges R. Management of gass pollen allergy with 5-gass pollen tablet: results of a 2-year real-life study. Adv. Ther. 34(6), 1382-1397 (2017).

22. Juniper EF, Thompson AK, Ferrie PJ, Roberts JN. Development and validation of the mini Rhinoconjunctivitis Quality of Life Questionnaire. Clin. Exp. Allergy 30(1), 132-140 (2000). 